\title{
Managed Care for Elderly People: A Compendium of Findings*
}

\author{
Edward Alam Miller, M.P.A., f Willam G.Weissert, Ph.D., and Michael Chernew, Ph.D.
}

University of Michigan, Ann Arbor, Michigan

\begin{abstract}
Although managed care seems to serve well the interests of non-elderly enrollees and their payers, elderly people face more risks. Chronic conditions, multiple problems, and more limited resonnes make thern more vulnerable, whereas multiple payer sources make them more complicated to cover. This synthesis of managed care delivered in Medicare and Hedicald demonstration projects serving elderly beneficiaries shows that managed care plams either select or attract enrollees who suffer fewer fraities than those served in fee-for-service settings, exhibit reluctance to enter nural makkets, provide a broad range of elderly-specific services, offer more compre. hensive coverage and services, and result in greater per-

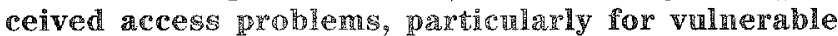
subgromps. $\mathrm{Plams}$ operate nore cheaply by using fewer

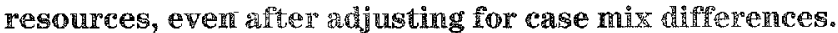
Managed care enrollees tend to be more satisfied with financial and coverage aspects, whereas fee-for-service entollees report higher satisfaction on other dimensions. In acute care settings, process of care filmdings were mixed, whereas climical and self-reported outcome indicators were no better and in some instances worse in managed care. Long-term care enmollees, in the few studies reported, consistently faited worse in bot the processes and outcomes of care. "These findings suggest that further research on the effects of managed care in its rapidly charling inearnations is needed, particularly
\end{abstract}

E. A. Miller is a Doctoral Student, Department of Health Management and Policy and Department of Political Science; Dr. Weissert is Professor, Department of Health Management and Policy, School of Public Health, and Research Scientist, Institute of Gerontology, and Dr. Chernew is Assistant Professor, Department of Health Management and Policy, School of Public Health, the University of Michigan, Ann Arbor, Michigan. 48109-2029.

* An earlier version of this paper was prepared as background report for the National Academy of Sciences, Institute of Medicine, Division of Health Care Services, Committee to Develop an Agenda for Health Outcomes Research for Elderly People, June 20, 1996, Washington, DC. The Institute was supported by the Greenwald Foundation. It was also presented to the Annual Meeting of the Gerontological Society of America, November 17-21, 1996, Washington, DC. Views expressed are those of the authors only, and do not necessarily reflect those of the Institute of Medicine, the Greenwald Foundation, or the University of Michigan.

†To whom correspondence should be addressed at the Department of Health Management and Policy, School of Public Health, University of Michigan, 109 Observatory, Ann Arbor, MI 48109-2029. with respect to lin to improve the quality of act and and long-term care delivered to elcherly people and the proper role of goverument and other key actors in the health care system.

Although elderly people report a high level of satisfaction with their acute health care and Medicare coverage (1), federal budget directors have called for major reform of a cost trajectory deemed unsustainable (2). Medicare is going broke; recent estimates indicate that the hospital trust fund is due to run out of money in 5 years (3). Expenditures might be reduced if the shift from institutional to ambulatory settings now broadly underway throughout the health care system can be enhanced and accelerated (4). Managed care promises such shifts, as well as fewer procedures performed and reduced use of expensive specialists.

Satisfaction with long-term care is much more problematic. Medicaid patients in particular suffer supply shortages, discrimination, a limited range of service options, highly fragmented care, and uneven or poor quality care $(5,6)$. For many elderly people, Medicaid pays all or part of their long-term care bill, provided they have first spent most of their monthly income on health care and related services. States lament that their spending for long-term care is driving out all other priorities save prisons (7). Eifforts to shift the site of long-term care from the heavily subsidized and expensive nursing home setting to home- and community-based settings and to better coordinate it through case managers have produced all but unalloyed disappointments when tested in a feefor-service (FFS) environment. Costs have tended to rise, not fall, whereas outcomes were but little bettered, typically for only small numbers of patients served, and usually for only the most fleeting periods $(8,9)$. Rationales for shifting from a FFS to managed care delivery system include improved service coordination, more precise targeting, cost-savings, and better acute and long-term care integration. If better managed, home care settings might too prove cost-effective (9). 


\section{PURPOSE AND CONTRIBUTION}

What impact would a shift toward managed care have on access, cost, and quality in the delivery of acute and long-term care services to elderly people? Although an important question given policymakers' increasing interest in the managed care approach, a comprehensive review that ties together the major research projects and demonstrations in this area is lacking. This article intends to fill this void by examining the American experience with managed care for elderly people in both the acute and long-term care settings and to determine whether or not the congeries of payment methods and organizational forms grouped under the broad rubric called managed care can indeed serve the interests of both payers and patients in ways which represent an improvement over current FFS approaches.

Although Health Maintenance Organizations (HMO) represent its most visible and well known configuration, managed care includes a variety of financing and delivery forms that fall along a continuum, ranging from FFS with utilization management to the sine qua non of managed care, the stafi model HMO. In general, as organization and payment become increasingly intertwined when moving from unmanaged FFS through managed care's alphabet soup, opportunities to monitor and control cost and quality typically increase (10). However, the common link in all forms of managed care is altered incentives for physicians and other providers, for enrollees, and for purchasers such as employers and government. Effects of these incentive changes are likely to touch access and coverage, the organization and management of care, patterns of use and allocation of resources, per capita and total spending, and a wide range of patient outcomes. It is these effects in the context of acute and long-term care for elderly people which are synthesized in this article. The published research literature is reviewed to garner what evidence there is documenting differences between managed care and FFS in terms of access, cost, and quality. The results indicate that although managed care organizations tend to provide a broad range of age-appropriate services to elderly enrollees, conserve resources, and operate at a lower cost than FFS, they tend to shun chronically ill elderly people or serve them poorly. Long-term care recipients do worse, although the state saves money.

\section{MAIOR PROGRAMS AND DEMONSTRATIONS}

Because managed care plans serve primarily nonelderly people, most studies exploring the impact of managed care on cost, quality, and access have focused on the experiences of those aged 65 and under (see Miller and Luft (11) for an overview). But elderly people have special needs associated with chronic conditions that require continuous rather than episodic care; many present with deficiencies in multiple systems; many lack social resources; and a high percentage are high cost patients. Not only is there a relative dearth of HMO experience in caring for elderly people, but the way in which health care is financed is much more complicated than finaneing for the under 65 population. For example, the primary payer for acute care services (Medicare or private insurance) depends on whether an individual continues to work or not. There may also be a secondary payer, either a policy paid for by the individuals themselves (Medigap), retiree health benefits, or Medicaid. Subacute services not covered by Medicare are either paid for by acute care insurance benefits, out-of-pocket, by Medicaid, or to a small but growing degree, by private long-term care insurance. In the context of managed care and elderly people, these disparate sources of financing need to be taken into account. For these reasons, results from studies using non-elderly enrollees may not be transferable to those 65 and over. In response, a number of Medicare and Medicaid programs and demonstrations have been implemented by the federal and state govermments to test the usefulness of managed care in slowing down expenditure increases in elderly populations.

Major evaluations include the Medicare At-Risk HMO program and related demonstrations (12-14), the Social Health Maintenance Organization study (S/HMO) (15), the Arizona Health Care Cost Containment System (AHCCCS) capitated acute care demonstration project $(16,17)$, the Arizona Long-Term Care System evaluation (ALTCS) demonstration, ${ }^{1}$ and the Program of All-Inclusive Care for the Elderly demonstrations (PACE) $(18,19)$. Much of the research reported here is based upon these demonstration projects and programs. Table 1 highlights important aspects of each.

\section{EFPECTS OF MANAGED CARE}

Theory suggests that managed care in the acute care environment should reduce hospital use and costs, emphasize primary and preventive care, discourage inappropriate use of services, and substitute less expensive care such as ambulatory, home health, and nursing home care for more expensive delivery settings. In the longterm care setting, it is expected to prevent hospitalizations and institutionalization of long-term care patients

\footnotetext{
${ }^{1}$ Although both the acute and long-term care programs technically fall under the same auspicies, the Arizona Health Care Cost Containment System (AHCCCS), we refer to the long-term care program as the ALTCS and the acute care program as the AHCCCS.
} 
Table 1

Descriptions of Major Managed Care Programs and Demonstrations

\begin{tabular}{|c|c|c|c|c|c|}
\hline & Medicare HMO & S/HMO & AHCCCS & ALTCS & PACE \\
\hline No. of enrollees & 4.5 million & $16,574^{a}$ & 448,000 & 20,361 & 2,700 \\
\hline No. of plans & 271 & 4 & 14 & 7 plans statewide & 11 \\
\hline Enrollment & Open/not mandatory & Open/not mandatory & Open/mandatory & Closed/mandatory & Open/not mandatory \\
\hline Eligibility requirements & Medicare eligible & $\begin{array}{l}\text { Medicare or dually } \\
\text { eligible; NFC to } \\
\text { receive LTC }\end{array}$ & $\begin{array}{l}\text { AFDC,SSI, other AZ } \\
\text { Medicaid eligible }\end{array}$ & $\begin{array}{l}\text { Family income below } \\
300 \% \text { of SSI and NFC }\end{array}$ & 55 or older and NFC \\
\hline Services covered & $\begin{array}{l}\text { Medicare Part A and } \\
\text { Part } B \text { acute care } \\
\text { services and cost- } \\
\text { sharing }\end{array}$ & $\begin{array}{l}\text { Medicare's basic } \\
\text { package and } \\
\text { additional services; } \\
\text { LTC for nursing } \\
\text { facility certified }\end{array}$ & $\begin{array}{l}\text { Primary, preventive, } \\
\text { and acute care }\end{array}$ & $\begin{array}{l}\text { LTC services, and acute } \\
\text { and other services not } \\
\text { covered by Medicare }\end{array}$ & $\begin{array}{l}\text { Acute, social, } \\
\text { preventive, and LTC } \\
\text { services }\end{array}$ \\
\hline Payment mechanism & $\begin{array}{l}\text { Capitation }=95 \% \text { of } \\
\text { average adjusted per } \\
\text { capita cost. Premium } \\
\text { for supplemental } \\
\text { benefits }\end{array}$ & $\begin{array}{l}\text { Capitation = Medicare, } \\
\text { Medicaid, and member } \\
\text { premiums }\end{array}$ & $\begin{array}{l}\text { Competitive bidding } \\
\text { and capitation } \\
\text { payment paid by } \\
\text { Medicaid }\end{array}$ & $\begin{array}{l}\text { Competitive bidding and } \\
\text { capitation payment paid } \\
\text { by Medicaid }\end{array}$ & $\begin{array}{l}\text { Capitation = Medicare, } \\
\text { Medicaid, and member } \\
\text { premiums }\end{array}$ \\
\hline Type of organization & HMOs and CMPs & $\begin{array}{l}2 \text { HMOs and } 2 \text { LTC } \\
\text { organizations }\end{array}$ & $14 \mathrm{HMOS}$ & $\begin{array}{l}2 \text { Arizona counties and } \\
5 \text { LTC organizations }\end{array}$ & Staff model HiNOs \\
\hline Legal authorization & TEFRA of 1982 & $\begin{array}{l}1115 \text { waiver, Medicare } \\
\text { waivers }\end{array}$ & 1115 waiver & 1115 waiver & $\begin{array}{l}1115 \text { waiver, Medicare } \\
\text { waivers }\end{array}$ \\
\hline
\end{tabular}

${ }^{a}$ Number of enrollees at the time of the program's major evaluation, the results of which are reported in this article.

${ }^{b}$ Open (beneficiary choice among managed care plans, or managed care and FFS); mandatory (beneficiaries must enroll in managed care).

cNursing facility certified; LTC, long-term care.

by supporting them in congregate living and home care settings, improving coordination of care, and providing patients with services uniquely required by a geriatric population.

Table 2 highlights the acute and long-term care focus of the studies reviewed, and briefly summarizes findings explored more fully below in terms of access, resource utilization and costs, and quality of care.

\section{ACGESS}

\section{Managed Care Plans Enroll Healhhier Individuals}

Findings in the research literature show that plans experience favorable selection (see Hellinger (30) for a pre1988 review of the literature). Riley et al. (31) found that the Medicare HMOs experienced mortality rates lower than expected when compared to the number of deaths in the local FFS sector. Lichtensten et al. (32) found no adverse selection but evidence of favorable selection in 19 of 22 Medicare HMOs studied using functional health status. Tax Equity and Fiscal Responsibility Act of 1982 (TEFRA) HMO evaluators Brown and Hill (28) reported that enrollees tended to be younger, less likely to be nursing home users or Medicaid recipients, and less expensive to care for than typical Medicare beneficiaries. Similarly, Riley et al. (33), using data from the Medicare Current Beneficiary Survey, found that, after controlling for demographic characteristics and area of residence,
Medicare HMO enrollees were less likely to report suffering from heart disease, functional limitations, and fair or poor health. Moreover, average predicted costs using measures of health status were much higher for FFS compared to HMO beneficiaries.

In PACE demonstration sites, despite 136 cumulative months of operation, only 888 clients were being served by the end of 1992, a figure well below program expectations, suggesting either niche marketing or skimming to its evaluators (55), although the evaluators also list a number of barriers to enrollment. According to program staff, barriers include client resistance to PACE's requirement of 4 or 5 adult day health center visits per week, client finances (e.g., unwillingness to pay copays, apply for Medicaid, or divulge information on personal finances), and loss of freedom of choice of providers. Still, as of 1995, PACE enrollment had grown to 2,700 individuals with an average age of 80.0 years and an average number of medical conditions and Activity of Daily Living dependencies of 7.8 and 2.7 , respectively (19). This indicates that despite any enrollment or selection problems it may be experiencing, the PACE program does serve a rather old and impaired client population.

Wisner et al. (34) offer rare dissension in reference to the Medicare HMO program, finding no evidence of favorable selection into HMOs in the Minneapolis market. To the extent that favorable selection exists, it might be due to the problem that sicker individuals are reluctant to suffer the disruptions of an existing physician rela- 


\section{Table 2}

Studies and Results

\begin{tabular}{|c|c|c|c|}
\hline \multirow{2}{*}{ Program or Demonstration } & \multirow[t]{2}{*}{ Reference } & \multirow[t]{2}{*}{ Focus } & Results ${ }^{a}$ \\
\hline & & & Medicare at-risk HMOs \\
\hline \multirow[t]{2}{*}{ Medicare capitation demonstration } & Garfinkel et al. (20) & Access & - Elderly w/Medigap less likely to switch to managed care (MC) \\
\hline & McCombs, et al. (21) & Cost & $\begin{array}{l}\text { + Total charges per month and costs for patients who died } \\
\text { lower in MC }\end{array}$ \\
\hline \multirow[t]{11}{*}{ Medicare competition demonstration } & Rossiter, et al. (22) & Cost & + Inpatient use lower for HMO enrollees \\
\hline & Retchin and Brown (23) & Process & $\begin{array}{l}\text { + Process indicator for routine and preventive care better for } \\
\text { HMOs }\end{array}$ \\
\hline & Retchin and Brown (24) & Process & $\begin{array}{l}\text { + Some process indicators better for colorectal cancer } \\
\text { patients in HMOs }\end{array}$ \\
\hline & & Process & $\begin{array}{l}\text { - Some process indicators worse for colorectal cancer } \\
\text { patients in HMOs }\end{array}$ \\
\hline & Retchin and Brown (25) & Process & $\begin{array}{l}\text { + Advice and 1-week follow-up for heart failure more likely in } \\
\text { HMOs }\end{array}$ \\
\hline & & Process & $\begin{array}{l}\text { Less frequent medication changes for some heart failure } \\
\text { patients }\end{array}$ \\
\hline & & Process & $\begin{array}{l}\text { nd Initial evaluation of heart failure patients similar in HMOs } \\
\text { and FFS }\end{array}$ \\
\hline & Retchin and Preston (26) & Process & $\begin{array}{l}+ \text { Eye care and urinalyses for diabetic patients more likely in } \\
\text { HMOs }\end{array}$ \\
\hline & & Process & - Flu shots for diabetics less likely in HMOs \\
\hline & & Process & $\begin{array}{l}\text { nd Complication management detection for diabetes similar in } \\
\text { HMOs and FFS }\end{array}$ \\
\hline & Retchin et al. (27) & Outcomes & $\begin{array}{l}\text { nd No difference in functional status decline among HMO and } \\
\text { FFS enrollees }\end{array}$ \\
\hline \multirow{9}{*}{$\begin{array}{l}\text { Medicare at-risk HMOs major } \\
\text { evaluation }\end{array}$} & Brown and Hill (28) & Access & - Favorable selection in HMOs \\
\hline & Brown et al. (14) & $\begin{array}{l}\text { Cost } \\
\text { Satisfaction } \\
\text { Satisfaction } \\
\text { Satisfaction }\end{array}$ & $\begin{array}{l}\text { + HMOs spent } 10.5 \% \text { less than if same enroliees were in FFS } \\
\text { - HMO enrollees less satisfied with all but a few dimensions } \\
+ \text { HMO enrollees more satisfied with cost and coverage } \\
+93 \% \text { of enrollees would recommend HMO to a friend } \\
\text { or relative }\end{array}$ \\
\hline & & Process & $\begin{array}{l}\text { + Speech and physical therapy for stroke patients more likely } \\
\text { in HMOs }\end{array}$ \\
\hline & & Process & $\begin{array}{l}\text { - Some process indicators worse for colon cancer and stroke } \\
\text { patients in HMOs }\end{array}$ \\
\hline & & Process & $\begin{array}{l}\text { nd No difference in some process indicators for colon } \\
\text { cancer patients }\end{array}$ \\
\hline & & Outcomes & $\begin{array}{l}\text { nd Similar outcomes for stroke and colon cancer patients in } \\
\text { HMOs and FFs }\end{array}$ \\
\hline & & Outcomes & $\begin{array}{l}\text { - Motor and speech defects greater in stroke patient } \\
\text { discharged from HMOs }\end{array}$ \\
\hline & Retchin et al. (29) & $\begin{array}{l}\text { Process } \\
\text { Process }\end{array}$ & $\begin{array}{l}\text { nd Similar signs of stroke upon admission in HMOs and FFS } \\
\text { nd Medications prescribed stroke patients similar in HMOs } \\
\text { and FFS }\end{array}$ \\
\hline & & Outcomes & nd Conclude stroke care outcomes similar in HMOs and FFS \\
\hline \multirow[t]{14}{*}{ Other Medicare studies and reports } & Hellinger (30) & Access & $\begin{array}{l}\text { - Evidence for favorable selection in HMOs in the pr-1988 } \\
\text { literature }\end{array}$ \\
\hline & Riley et al. (31) & Access & $\begin{array}{l}\text { - Death rates lower in HMOs than FFS, possible } \\
\text { favorable selection }\end{array}$ \\
\hline & Lichtenstein et al. (32) & Access & - Favorable selection in HMOs studied \\
\hline & Riley et al. (33) & Access & $\begin{array}{l}\text { - HMO enrollees report better health and exhibit lower } \\
\text { predicted costs }\end{array}$ \\
\hline & Wisner et al. (34) & $\begin{array}{l}\text { Access } \\
\text { Access }\end{array}$ & $\begin{array}{l}\text { nd No favorable selection in HMOs studied } \\
- \text { HMOs dropped rural counties and enrollees }\end{array}$ \\
\hline & Iverson et al. (35) & Access & - HMO reluctance to care for seniors \\
\hline & PPRC (12) & Access & $\begin{array}{l}+ \text { Rapid growth in the number of at-risk contracts since } \\
1991 \text { Access }\end{array}$ \\
\hline & & Access & $\begin{array}{l}\text { + Most HMOs offer supplemental benefits at no } \\
\text { additional charge }\end{array}$ \\
\hline & Ricketts et al. (36) & Access & - Rural areas have less access to HMO services \\
\hline & HMO-PPO Digest (37) & Access & + HMOs willing to affiliate with elderly relevant services \\
\hline & Hurley and Bannick (38) & Access & $\begin{array}{l}\text { + HMOs willing to affiliate with nursing homes and other } \\
\text { providers }\end{array}$ \\
\hline & Friedman and Kane (39) & Access & + HMOs willing to hire geriatric-oriented professionals \\
\hline & Fox, Heinen and Kramer (40) & Access & + HMOs willing to develop LTC-elderly relevant services \\
\hline & Eppig and Poisal (41) & Access & $\begin{array}{l}+ \text { HMO enrollee expenditures for prescription drugs half that } \\
\text { of FFS }\end{array}$ \\
\hline
\end{tabular}


Table 2-Continued

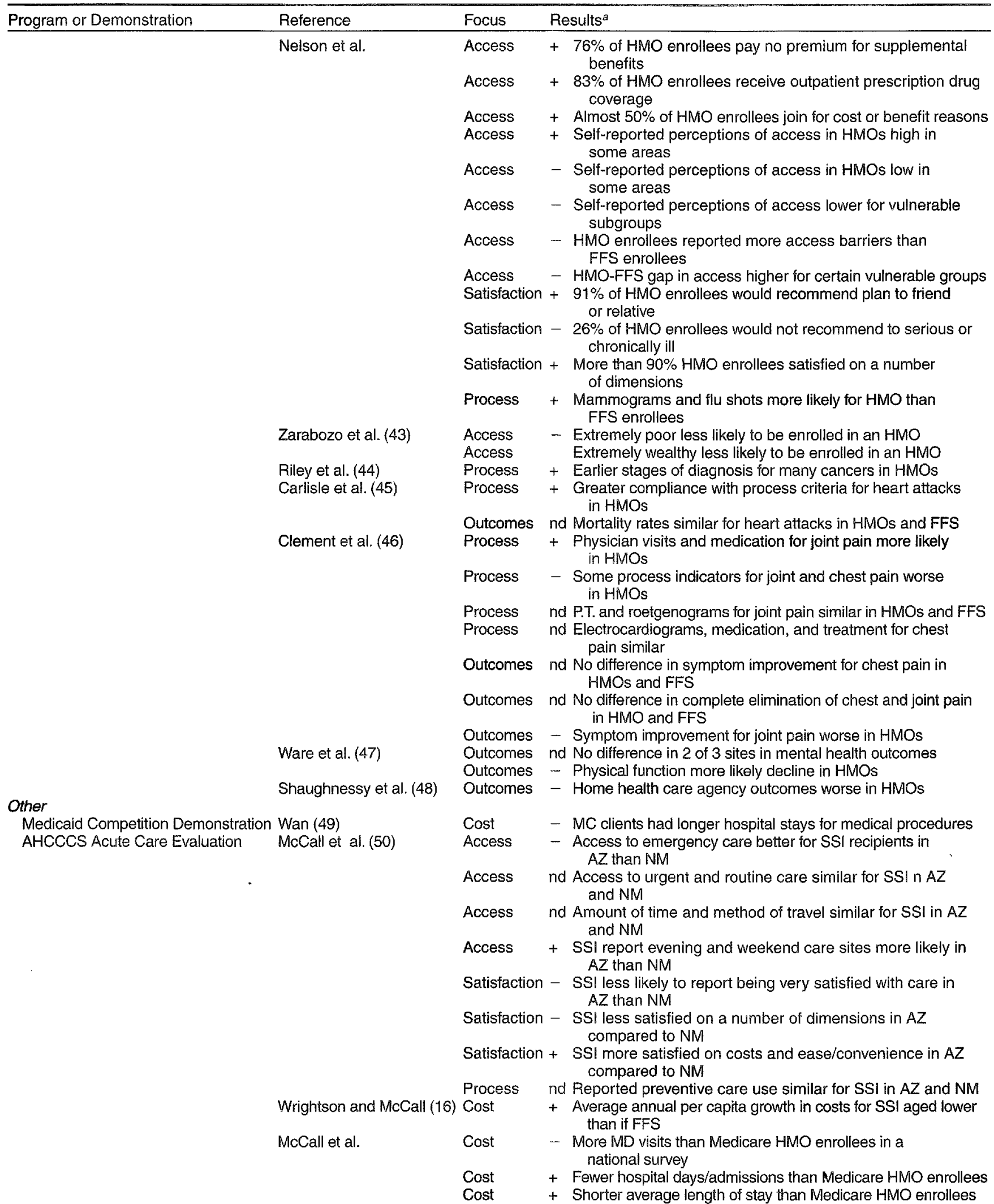




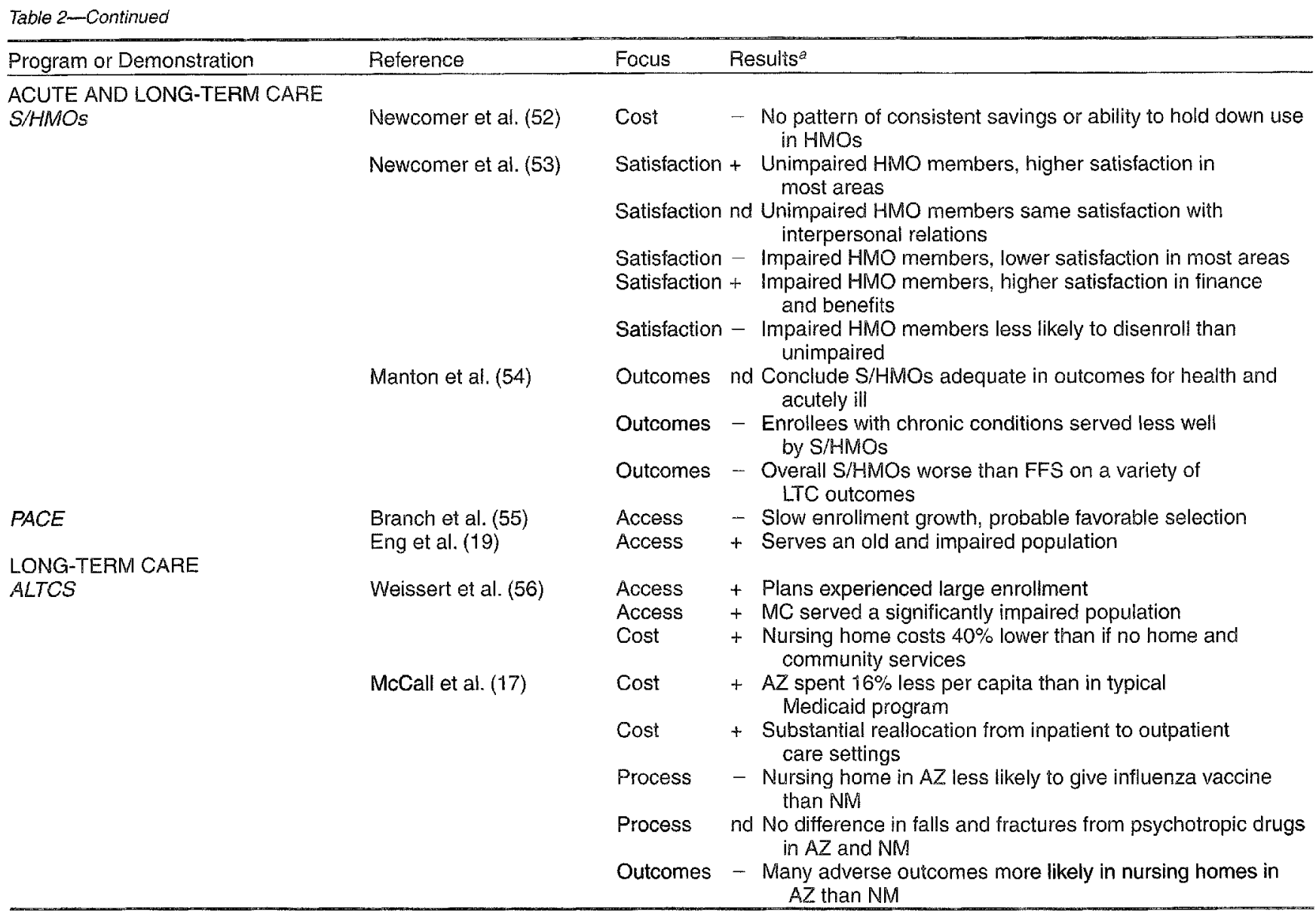

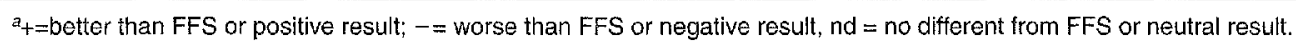

tionship which is often required when enrolling in a closed panel HMO. Only healthier seniors may be willing to make such a switch. Alternatively, it might be due to efforts by managed care organizations to discourage sicker individuals from enrolling. Most studies do not attempt to elucidate the causal factors behind favorable selection. In either case, favorable selection raises questions about managed care's viability for serving a frail and chronically ill elderly population, particularly those in need of longterm care. One response developed very recently by state Medicaid programs for their nonaged populations may also work for aged people, however, although it has not yet been applied to aged populations. A single contractor is hired as a broker, charged with recruitment, patient counseling about options, and assignment of the patient to a managed care plan which is required to accept all Medicaid patients assigned by the broker.

Despite evidence of favorable selection, a survey of managed care plans (35) found a high level of reluctance among managed care plans to assume the risk of caring for senior citizens. Plans feared unlimited liability for care, weak demand, and adverse selection. In deference to trepidations such as these, S/HMO sites were allowed to limit the number of individuals with one or more activities of daily living impairments to $5 \%$ of enrollment. Nevertheless, recent evidence from the Medicare risk program indicates that such attitudes may be changing; the number of plans entering into such contracts increased from a low of 93 in 1991 to 271 in 1996 (12). The ALTCS, a Medicaid program capitated for the state's poor population, had 20,361 enrollees as of July 1, 1995, and served a significantly impaired population; $72 \%$ of homeand community-based enrollees and $96.7 \%$ of $1990-1991$ skilled nursing facility clients were dependent in toileting or eating, the highest level of dependency (56). This compares to $65.4 \%$ of 1985 National Nursing Home Survey residents who were similarly disabled (57).

\section{Managed Care Might Not Wort in Rural Areas}

Despite managed care's potential, it may not work in sparsely populated areas. Ricketts et al. (36) make the 
point that "Some types of plans require a threshold number of subscribers to support capital needs or provide some actuarial basis for distributing risks." "They note that higher county population density is strongly associated with better access to HMO services, with adjacency to a metropolitan county strongly predicting whether or not a rural county is included in the service area of an HMO. This is a critical point, they report, because during the last U.S. Census, more than a quarter of elderly Americans were found in rural areas, and they tended to be sicker and more impaired than urban dwellers.

Two of four HMOs in the Twin Cities area dropped their rural counties and enrollees in 1988 after finding that covering them was no longer profitable. Claims vary as to why. Either (the plans' view) Heath Care Financing Administration (HCFA) paid too little for rural enrollees (it paid less than for urban enrollees), or (a cynical view) enrollees began to use services for the first time (34).

\section{Benetits May Be Age-Approphate and More Comprohamsine}

A recent survey of HMOs (37) showed arrangements had been made for the following elderly-relevant services: home health (91\%), pharmacies (81\%), nursing home (75\%), hospices (30\%), rehabilitation centers $(26 \%)$, and subacute care facilities (12\%). Other studies have shown a willingness to affiliate with nursing homes and other aging network providers (38), to hire geriatricians and geriatric nurse practitioners (39), and to develop long-term care and other aging-relevant services (40). On the acute-care side, Medicare HMOs provide more extensive coverage than Medicare's tradilional FFS package. In fact, most offer supplemental benefits in the way of additional services or coverage for Medicare costsharing, and although they could charge a premium for these add-ons, only one-third do (12). Take prescription drugs, for example. The Medicare Current Beneficiary Survey shows that although prescription drug use rates are similar for Medicare FFS and HMO beneficiaries, ontof-pocket prescription drug expenditures for $\mathrm{HMO}$ enrollees are half that of FFS enrollees (41). Similarly, a 1996 Physician Payment Review Commission (PPRC) sponsored survey by Mathematica Policy Research of beneficiaries enrolled in Medicare risk plans found that more than three-quarters paid no premium and that $83 \%$ received coverage for outpatient prescription drugs, a benefit not covered by Medicare's traditional package of benefits (42).

Indeed, many elderly beneficiaries enroll in managed care to obtain coverage for a broader range of services. The Medicare Capitation Demonstration found that in- dividuals with a Medigap policy were less likely to make the switch to managed care from FFS (20). More recently, 1993 data from the Medicare Current Beneficiary Survey indicate that those with incomes below $\$ 10,000$ per year are less likely to be enrolled in HMOs, most likely due to their status as Medicare-Medicaid dually eligibles, whereas wcalthy enrollees are also less likely to be so enrolled, possibly reflecting the limited attractiveness of supplemental HMO benefits (43). Approximately $50 \%$ of at-risk beneficiaries surveyed in the 1996 PPRC-sponsored study by Mathematica indicated that costs or benefits represented their primary motivations for joining (42).

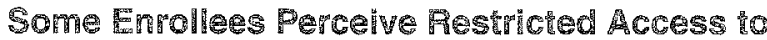 Sarvices}

The 1996 PPRC-sponsored study found that the vast majority of Medicare risk plan entollees saw a physician during the previous year, rated continuity of care highly, believed plans provided enough information upon initial enrollment, and perceived no barriers to access such as care delays, language problems, or lost or misplaced medical records. Few reported problems obtaining access to hospital care, specialty care, or home health care. On the other hand, many beneficiaries reported that they had problems gething questions answered, were unaware of their rights to appeal plan decisions, and were not encouraged to have a physical examination or health assessment after joining. The researchers also found that vulnerable populations such as those over the age of 85 , non-elderly disabled people, functionally impaired people, those in fair or poor health, and those in worsening health, experienced more access problems than their less vinerable counterparts (42).

Using the Medicare Current Beneficiary file as a comparison group, the researchers found that risk plan enrollees experienced more access problems than their counterparts in FFS. Although $13.3 \%$ of managed care enrollees reported at least 1 of 6 access problems surveyed, just $4 \%$ of FFS beneficiaries answered affirmatively when asked if they had trouble obtaining health care when they wanted or needed it (42). The gap in perceived barriers to access between $\mathrm{H}$ MO and FFS enrollees widens for certain groups such as the non-elderly disabled ( $24.9 \%$ versus $14.1 \%$ ), those over the age of 85 ( $16.1 \%$ versus $3.1 \%$ ), and those in fair or poor health ( $23.6 \%$ versus $9.3 \%$ ). In short, problems getting wanted services are likely to be experienced by a substantial percentage of chronically ill people if they enroll in managed care.

Of course this assumes that FFS represents the gold standard, which is not necessarily the case. Indeed, in- 
terest in managed care has been driven primarily by its purported ability to hold down potentially avoidable resource use and costs. For policymakers, the challenge is to maintain an acceptable level of access and quality while tapping managed care's potential to achieve their budgetary objectives.

Evaluators of the acute care portion of the AHCCCS program found a nonstatistically significant difference in the access of Social Security Income (SSI) recipients to emergency care in the Arizona (prepaid) and New Mexico (FFS) Medicaid programs in 1985. Of those who "reported that they needed emergency care" in Arizona, $19.9 \%$ reported that they had "any difficulty" in getting it, compared to $13.3 \%$ in New Mexico (50). There was no statistically significant difference in access to urgent care or routine care, however, or in the method or amount of time it took to get to the usual place where care is received. However, SSI recipients in the AHCCCS program were more likely to report that the place where they usually receive medical care had at least one care location open in the evenings or weekends. The evaluators note that this difference may be just the kind of appropriate shift of resources most desired from managed care.

\section{RESOURCE USE AND COSTS}

\section{Utilization and Costs Are Reduced or Shifted}

In the Medicare Competition Demonstration, hospital inpatient use was lower for managed care enrollees compared to FFS enrollees in both discharges and days per 1,000 enrollees (22). Others (21) found total charges per month in an old group-HMO participating in the Medicare Capitation Demonstration program to be nearly $40 \%$ lower than FFS, whereas costs incurred by patients who died were $27 \%$ below that of their FFS counterparts.

Mathematica and Virginia Commonwealth University researchers (14) found that TEFRA HMO enrollees had the same number of hospital admissions, but a lower average length of hospital stay than did FFS clients. HMOs were more likely to be discharged to lower cost settings. For example, HMO stroke patients were more likely to go to nursing homes and less likely to go to more expensive rehabilitation hospitals, whereas HMO colon cancer patients were more likely to be discharged to their own homes than to nursing homes or rehabilitation hospitals (14). Moreover, HMO enrollees, discharged more often to these alternative settings, experienced shorter skilled nursing facility visits. The authors also found a $50 \%$ reduction in home health visits but no difference in the number of clients receiving such care. The greatest HMO versus FFS decrease in hospital days and home health visits was for enrollees with poor health, dependent in activities of daily living (personal care) or instrumental activities of daily living (grooming, cooking, and so forth), or who died within 9 months of the interview (14).

In some cases, these researchers found that HMO enrollees were more likely to consume certain services. For example they were more likely to visit a physician once a year and have a physical examination. However, fewer HMO enrollees visited a physician once a month or more. To a small degree, HMO enrollees were more likely to have a skilled nursing facility stay (28). The probability of admission for enrollees in poor health or with functional impairments increased for HMO enrollees compared to FFS clients.

Despite the variation in findings across different services, the team's overall conclusion was that, after adjusting for favorable selection and insensitive capitation payments, HMOs in the study spent about $10.5 \%$ less for hospital, physician, home health, and skilled nursing care than would have been spent for the same enrollees in a FFS payment system (14). Critics have noted that results were based on only first year enrollees. Results might differ over a longer period of observation.

Evaluators estimated that between 1983 and 1993 the acute care side of the AHCCCS saved $\$ 196,741$ million compared to what would have been spent if a traditional Medicaid program had been operating in the state (16). However, only a little more than $\$ 7,022$ million in these savings were generated by aged SSI recipients (most came from Aid to Families with Dependent Children eligibles and the SSI disabled). Still, the average annual per capita growth for aged SSI recipients over the 11 years studied was less for the AHCCCS (13.7\%) than if a traditional Medicaid program had been in place (15.3\%). A comparison of SSI/Medicare recipients in the AHCCCS from October 1987 to March 1989 to Medicare enrollees in HMOs surveyed by the Group Health Association of America in 1987 found that the former had one more physician encounter per member per year but $26 \%$ fewer hospital days, $11 \%$ fewer admissions, and a $14 \%$ shorter average length of stay (51).

In the ALTCS, McCall et al. (17) found a roughly $16 \%$ average annual reduction in what Arizona spent per capita for elderly and physically disabled long-term care Medicaid patients from what would have been spent in a typical Medicaid program. Most of the savings came from reduced hospital and nursing home use, which was less than offset by higher ambulatory care and administrative expenses. In that same evaluation of the ALTCS, Weissert et al. (56) concluded that nursing home costs were probably $40 \%$ lower than they would have been without several important plan features including capitation, 
stringent eligibility screening, an extensive array of homeand community-based services, strong financial incentives to make placements in home and community care rather than mursing homes, and very low payments for home care services. McCall et al. (17) found no difference in the overall level of services consumed, but a substantial reallocation from inpatient to outpatient. (But quality problems resulted, see below and Table 2.)

An exception to the usual pattern of lower inpatient use was reported by Wan (49) who found that dually eligible Medicaid managed care demonstration clients had longer hospital stays for medical procedures than did FFS comparison group members. Similarly, results varied across $\mathrm{S} / \mathrm{HMO}$ sites depending on enrollee disability, market competition, premium rates, and level of expanded benefits, but in general did not show a pattern of consistent savings or a consistent ability to hold down impatient and institutional use (52).

Despite exceptions, the general pattern of findings suggests cost savings in acute care settings associated with managed care. Care seems to be rationed in situations in which it can be rationed, and provided more generously when it may prove efficacious. As noted above, however, cnrollees may not always agree with rationing decisions.

\section{OULITY OF CARE}

Researchers have focused on various criteria for measuring quality, such as enrollee satisfaction, the processes of care (preventive care use, emergency care use, early detection and diagnosis, screening, care management, continuity, appropriateness, post-discharge planning), and the outcomes of care (pain and suffering, post admission complications, functional status decline or recovery, and mortality). Although the results of these studies are mixed, they can be summarized as showing managed care enrollees less satisfied on most dimensions but financing and coverage, no clear systematic difference between the managed care and FFS performance on acute care processes, worse cinical and selfreported outcomes in acute managed care, and a consistent inferiority in terms of both the processes and clinical outcomes of long-term care in the few studies based in such settings.

\section{Enrollee Satน}

Enrollees Satisfect werth Mardaged Care. Although researchers have generally found that elderly people rate their overall satisfaction with both HMO and FFS delivery highly, HMO enrollees typically report being more satisfied than FFS beneficiaries with the financial and coverage aspects of their plans and less satisfied with most other dimensions. Thus, a comparison of Medicare IMO and FFS beneficiaries found the former to be less satisfied with the care process, plan access, provider choice, and perceived quality and outcomes, but significantly more satisfied with costs while being less likely to report lacking coverage for needed services (14). Results from the S/HMO study showed similar results but for impaired enrollees only. Although unimpaired members reported higher satisfaction than FFS beneficiaries in all areas except interpersonal relations (where there was no difference), impaired enrollees reported lower satisfaction in all areas but finance and benefits (where they were more satisfied) (53). In 1985, evaluators of the acute care side of the AHCCCS found that SSI recipients in the Arizona Medicaid program were less likely to report being very satisfied with their overall medical care compared to their counterparts in New Mexico ( $56.1 \%$ versus $73 \%$ ) (50). In particular, Arizona respondents reported being slightly less satisfied, on average, with waiting time, evening and weekend availability, information giving, and courtesy and consideration. Alternatively, Arizona respondents reported being slightly more satisfied, on average, with ease and convenience and costs paid out of pocket for medical care received.

Both the TEFRA and S/HMO evaluators concluded that lower costs and more comprehensive benefits tended to offset lower satisfaction with other attributes. Thus, approximately $93 \%$ of respondents in the TEFRA evaluation said that they would recommend an HMO to a friend or relative, whereas impaired elderly people were less likely to disenroll than their unimpaired counterparts $(14,53)$. Although the 1996 PPRC study similarly found that $91 \%$ of Medicare HMO beneficiaries would recommend their plan to a friend or relative, close to one-quarter indicated that they would not do so for someone who was seriously ill or suffered from a chronic condition (42). Nevertheless, more than $90 \%$ ranked their plans as excellent or very good/good on dimensions such as coverage, waiting time, choice of specialists, value for money, and ease seeing a primary care physician of choice.

\section{Procoss of Care}

Process of Care Findirugs Are Mixed. Many studies employed process of care and resource use indicators as quality measures. The connection between resource use and quality depends crucially on the perceived appropriateness of the service in question. On the one hand, reduced utilization might represent improved quality due 
to decreased use of inappropriate services. On the other, it may mean a reduction in necessary services.

Some Acute Managed Care Processes of Care Were Better: (a) A study of the eight Medicare Competition Demonstrations showed that they were more likely to provide elements of routine and preventive care and examine occult blood and endoscopy or barium enemas among colorectal cancer patients $(23,24)$. (b) Riley et al. (44) found earlier stages of diagnosis in Medicare HMO enrollees compared to FFS clients for breast cancer, cervix, colon, and melanomas. No differences were found for prostate, rectum, buccal cavity and pharynx, bladder, uterus, kidney, and ovary cancers. The authors concluded that "HVO enrollees were diagnosed at, earlier stages for cancer sites for which effective screening services are available" (44). The strongest HMO-FFS differences were found in those geographic areas with the largest and most mature HMOs. (c) Compliance with process of care criteria for Medicare beneficiaries with acute myocardial infarction was found to be greater among Medicare HMO than FFS providers (45). (d) Clement et al. (46) found that, among individuals with joint pain, physician visits and medication were more likely to be prescribed in the Medicare HMOs. (e) Congestive heart failure patients were more likely to receive advice on salt intake and have a 1 week follow-up after discharge in eight Medicare Competition Demonstration HMOs (25). Similarly, HMO enrollees with diabetes were more likely to receive aspects of eye care and urinalyses (26). (f) The TEFRA HMO evaluation showed that stroke patients were more likely to have post discharge speech and physical therapy planned (14). (g) The 1996 PPRC sponsored survey by Mathematica found that many beneficiaries were encouraged to obtain preventive care; $22 \%$ reported receiving a hearing test and $71 \%$ a cholesterol test, with glaucoma tests, flu shots, mammograns, and colorectal cancer screening falling somewhere in between. Using the Medicare Current Beneficiary Survey for comparison, the researchers found that HMO enrollees were more likely to obtain a mammogram and flu shot than their FFS counterparts (42).

Other Acute Managed Care Processes of Care Were Worse. (a) Evaluation of eight Medicare Competition Demonstrations showed longer delays between presenting symptoms of gastrointestinal bleeding and diagnosis as well as greater preoperative imaging for colorectal cancer patients (24). (b) A comprehensive evaluation of the TEFRA program found a shorter distance between tumor and the margin of resection in colon cancer patients (14). (c) A Medicare risk program study showed that specialist referrals, follow-up recommendations, and progress monitoring were more likely among FFS beneficiaries with joint and chest pain (46). Those with chest pain in a FFS setting were also more likely to receive physician visits. (d) A study of eight Medicare Competition HMOs showed less frequent changes in medication for congestive heart failure patients with uncontrolled hypertension in the HMO compared to FFS setting (25), whereas $\mathrm{FFS}$ clients with diabetes were much more likely to receive flu shots (26). (e) The TEFRA evaluation showed that HMO clients with stroke and colon cancer had fewer tests, procedures, and services, and a shorter average length of stay, and less time in intensive care units. For example, stroke patients in the HMO setting received less physical therapy in the hospital (14).

Still Other Acute Managed Care Processes of Care Were No Different. (a) The TEFRA evaluation found similar signs of stroke upon admission to indicate no delay in urgent hospitalization in the HMO relative to the FFS setting (29). (b) Clement et al. (46) found no difference in physical therapy prescription and roentgenograms performed among Medicare HMO and FFS beneficiaries with joint pain, and no difference in electrocardiograms perfomed, and medication and treatment prescribed among those with chest pain. (c) Retchin et al. (25, 26) found little difference in the initial evaluation of congestive heart failure patients, whereas among elderly people with diabetes, similar management and complication detection strategies characterized the eight Vedicare Competition Demonstrations sites and their FFS counterparts $(25,26)$. (d) Retchin et al. (29) reported that significant differences did not exist in the medications prescribed to stroke patients in TEFRA HMOs compared to FFS. (e) TEFRA evaluators noted that most indicators of quality for colon cancer showed no difference (amount of colon removed, blood lost, number of lymph nodes removed) (14). (1) Evaluators of the acute care portion of the AHCCCS found no difference in the receipt of preventive care (physician, eye and dental examinations, blood pressure check, pap smear, and breast examination) between Arizona and New Mexico SSI recipients in their respective Medicaid programs in 1985 (50).

Some Long-Term Managed Care Processes of Care Were Worse. An evaluation of the ALTCS found that nursing home residents in Arizona (all of whom were enrolled in managed care) were less iikely to be offered influenza vaccine than were Medicaid nursing home residents in New Mexico (17). (Evaluators warned that although the overall results of this study seem to indicate that the quality of care in the capitated system was lower, the findings could have been influenced by sample selection, data collection methods, less than perfect quantification of independent variables, and by the choice of quality indicators.) 
Other Long-Term Managed Care Processes of Care Were No Different. No significant differences existed between ALTCS nursing home residents and the New Mexico control group with respect to the incidence of patient falls or fractures in the use of psychotropic drugs (17).

\section{Chinical and Self-Peported Outcomes of Care}

Most Acute Managed Care Outcomes Were No Better than FFS, Whereas Some Long-Terme Mrnagged Core Ontcomes Were Worse. Most evaluations did not find major differences in the acute care quality between HMO outcomes and those observed in the Medicare, FFS system. However, in some cases, subsets of these findings suggest that acute care quality in HMOs, as measured by outcomes, might be below that received by FFS beneficiaries. Moreover, the few studies examining Iong-term care outcomes provide evidence for the assertion that FFS providers performed better than their HMO counterparts.

Some Acute Managed Care Outcomes Were No Different. (a) Ware et al. (47) compared the 4-year change in summary mental health scores from the Medical Outcomes Study 36-Item Short-Form Health Survey among Medicare beneficiaries served in an HMO or FFS setting in three study sites (Boston, Chicago, and Los Angeles). After controlling for demographic, chronic disease, and study design factors, the authors found that the 346 elderly HMO patients included in the situdy were more likely than the $476 \mathrm{FFS}$ patients to report better mental health outcomes after 4 years (26\% and 13\%, respectively, $P<0.03$ ). The authors point out, however, that this result was "due entirely to the better performance of HMOs in one study site." In the other two sites, no differences were found between Medicare beneficiaries in HMOs and FFS. (b) Based on their overall observations from the TEFRA study on stroke care, these evaluators concluded that quality is equal in HMOs and FFS. Moreover, they stress that HMOs seem to economize on inpatient care without affecting outcomes (29). (c) Manton et al. (54) determined that S/HMOs perform adequately with respect to the healthy and acutely ill in view of various health outcomes. (d) Carlisle et al. (45) found no difference in mortality rates due to acute myocardial infarction in Medicare HMOs and FFS. (e) Clement et al. (46) found no difference between Medicare HMO and FFS enrollees in the likelihood of symptom improvement among those with chest pain as well as no difference in the complete elimination of joint and chest pain. (f) Retchin et al. (27) found no difference in functional status decline between HMO and FFS enrollees in the Medicare Competition Demonstrations. (g) An evaluation of the TEFRA program found similar death, hospital readmission, and post-admission complication rates among colon cancer and stroke patients within the HMO and FFS settings (14).

Some Acute Managed Care Outcomes Were Worse. (a) Ware et al. (47) found that the 346 elderly HMO patients included in the study were more likely than the 476 FFS patients to report a decline in physical health outcomes after 4 years (54\% and $28 \%$, respectively, $P<0.001$ ). Moreover, such decline existed in all three study sites examined. (b) Shaughnessy et all. (48) compared the outcomes of patients served by nine Medicare risk HMO-owned home health care agencies, 15 pure FFS agencies, and 14 mixed/contractual agencies (i.e., those that serve a significant number of both HMO and FFS beneficiaries) located in 18 states. The authors compared HMO and FFS patients across a variety of outcomes, including status improvement and stabilization (using such indicators as activities of daily living and instrumental activities of daily living), mortality, discharge to independent living, hospitalization, and discharge to hospital for emergent or urgent care. The author's conclude that case-mix-adjusted outcomes of home health care are better for FFS than IMO patients. They found that: "... an overall trend of superior case-mix-adjusted outcomes for FFS patients was apparent in terms of the relative uniformity of higher values for most outcome measures and... they nearly always indicated superior outcomes for FFS patients." Favorable outcomes for FFS were found for a wide variety of outcomes including activities of daily living such as eating, toileting and transferring, instrumental activities of daily living such as grooming and shopping, and medications management. (c) Clement et al. (46) found that symptom improvement was more likely to occur among Medicare FFS than HMO beneficiaries with joint pain. (d) The TEFRA evaluation revealed that stroke victims had greater motor and speech defects at discharge in HMOs (although no difference in sensory deficits) (14).

Some Long-Term Managed Care Outcomes Were Worse. (a) Nursing home residents in the ALTCS program were more likely to experience a decubitus ulcer, fever, and catheter insertion than nursing home residents served by the New Mexico Medicaid program (17). (b) Manton et al. (54) concluded that S/HMOs do not perform well for impaired or acutely ill individuals with chronic impairments. Moreover, they assert "that LTC services provided in S/HMOs were not effective in improving... functional status-especially among elderly females who have the greatest LTC needs" (54). Overall, FFS female patients had a significant advantage in life expectancy; likewise, FFS male patients also experienced outcome advantages (54).

\section{SUMMARY OF EFFECTS}

Although some studies divert from a common theme, most point to at similar set of conclusions: (a) managed 
care provides more comprehensive coverage and services to healthy patients and provides a broad range of age-appropriate services to elderly enrollees; (b) managed care restricts access, particularly for chronically ill elderly people and those in rural areas, and experiences favorable selection and attrition so that its case mix is less debilitated than the average population (although there are important exceptions and a growing willingness to enroll very sick people among some organizations as well as new methods of controlling favorable selection, at least in mandatory systems); (c) managed care conserves resources and it operates at lower cost (although savings may remain within the managed care firm, depending upon the payment agreement in place); (d) managed care receives lower satisfaction ratings on all dimensions but financial and coverage aspects of plans and such ratings vary with degree of impairment;

(e) managed care sometimes performs better and other times worse in terms of acute care processes; (f) managed care produces acute care outcomes which are no better and possibly worse than those found in the FFS sector; and (g) managed care does worse on the basis of process and outcome indicators in treating the conditions of a chronically ill, frail elderly population in both nursing homes and home health settings.

\section{FUTURE RESEARCH}

The total number of studies addressing managed care in an elderly population is scant and each is fraught with problems ranging from selection bias to concerns about generalizability from settings which may be unique in many respects. Within these limitations, however, preliminary results indicate that managed care offers substantial promise for reducing costs of caring for elderly people. They also indicate that favorable selection will occur if not constrained by payer policies, brokers, or ameliorated by incentives that make managed care more attractive to chronically ill people. Quality of care findings are a particular concern, indicating that care processes and outcome in acute and especially long-term care settings need considerable attention and improvement. Researchers must move beyond their previous focus on managed care's average performance for the elderly and begin to emphasize its effects on the most frail and chronically ill. In view of significant government involvement in financing acute and long-term care for those 65 and over through Medicare and Medicaid, the government role in structuring its relationship with managed care contractors needs to be more carefully elucidated.

In short, many important questions remain, ranging from validity and generalizability of findings accumulated thus far to concerns barely addressed in past re- search, such as the appropriate role of government. Specifically, better research designs are badly needed to substantiate old results and produce valid new ones. The research agenda remaining is substantial and should include more rigorous longitudinal designs, more representative studies, and more rural studies. Especially needed are randomized controlled trials. Although these are difficult to mount among Medicare beneficiaries, a number of precedents exist, including many in long-term care (e.g., see Refs. 58-60). Beneficiaries can be offered expanded services in a managed care plan, then be randomly assigned to managed care or traditional FFS if they grant informed consent to participate in the study. Without randomized trials, there is no way to overcome the nagging uncertainties engendered by selection biases. Oddly, current policy demands such a level of rigor for new drugs, but so far not for a change which would seem to result in heretofore unprecedented major shifts in care practices.

Equally lacking in the studies to date is any systematic testing of the relationship between managed care plan features and care processes and outcomes. Resource allocation decision-making rules employed by plans should be made explicit to permit study of their effects on cost savings on the one hand and consumer satisfaction on the other. Although the field needs more time to mature before rigid regulatory procedures lock out further innovations, studies to date lack any systematic effort to identify plan features which deserve to be adopted versus those which seem to be associated with inferior performance. More needs to be known about the role of quality assurance programs employed in each of the demonstrations and study plans. Even less is known about the relationship between the existing regulatory enviromment and performance of plans' quality assurance mechanisms.

Other plan features and practices affect who enrolls in plans. More systematic study is needed of how plans market themselves, to whom, with what level of vigor, and what barriers to entry they erect or fail to overcome which tend to result in favorable selection into most plans. Aspects may include features of selection of physicians for their panels, types of benefits provided and limits on their availability, access to primary and specialty care providers, where the plans locate themselves and their providers, what information they give to prospective enrollees, and other aspects of their recruitment and enrollment process. Of particular interest is the potential for enrollment brokers to serve as unbiased agents of the payer to assure that all enrollees receive equal treatment and information about their plan options. A particular concern with the enrollment process is the need to develop enticements with which to encourage 
enrollment of a broader range of seniors, especially chronically ill enrollees and those living in rural areas.

Much better methods of matching payment to costs of delivering care are needed. Clearly the current AAPCC formula overpays managed care plans and so was revised in the 1997 Balanced Budget Agreement. Its effects are as yet unknown and likely to be complex. Yet the challenge is to continue to encourage plans to offer senior-attracting services while not resulting in excess profit. HCFA's plans to further experiment with the competitive bidding approach used in the Arizona Medicaid demonstration projects offers substantial promise and should be studied. Indeed, competitive bidding is just one aspect of a largely missing ingredient in research to date, the appropriate role of government in steering and regulating the managed care field. How should govermment respond when $15 \%$ of enrollees report that they are underserved by their managed care plan? Will market forces solve the problem? Is it a concern of government when freedom of choice of provider is restricted, care is denied, plans reject powerful or popular providers, hospitals close, nonenrolled beneficiaries' premiums, co-pays, and other out-of-pocket expenses rise, and plans fail?

A similar set of questions could be asked about the role of consumer advocacy groups and the foundations which sometimes support them. Clearly they must become expert in interpreting the implications of incentives built into capitation formulas. They must identify tracer conditions and subgroups likely to be ill served by managed care and learn to monitor and advocate on their behalf. And they must become sophisticated in evaluating research findings on the relative effectiveness and efficiency of some care modalities relative to others if they are to avoid losing or meaningless battles for care likely not to be worth the fight. Groups such as the American Association for Retired Persons regionall, state, and local groups and the Citizens' Coalition for Better Care must learn to interpret provisions of public bid solicitations, selection criteria used to choose plans, contract requirements determining the nature of provider networks, and details of benefit requirements including service definitions and quality assurance requirements imposed by states on Medicaid plans and plans on their providers. Are these realistic roles for consumer groups advocating on behalf of elderly enrollees, and if so, what are the best ways in which to train staff and volunteers to play these important roles?

These pressing questions remain largely unanswered although they lie behind policy choices faced on a daily basis by policy makers considering the appropriate role of managed care in caring for elderly enrollees in Medicaid, Medicare, and retiree health plans. A sub- stantial research agenda should be undertaken directed less at answering the question of how well managed care performs compared to FFS arrangements, but rather how to design managed care so that it performs at least as well as FFS care at lower cost, and how to most effectively use the other actors in the health care system to help shape managed care to make it most effective, efficient, and satisfactory to chronically ill elderly people and other vulnerable populations.

\section{References}

1. Vladeck BC, King KM. Medicare at 30: Preparing for the future. JAMA 1995;274:259-262.

2. Darman $\mathbb{R}$. Comprehensive Health Reform: Observations about the Problem and Alternative Approaches to Solution. Presented to the House Committee on Ways and Means, October 10, 1991.

3. The Board of Trustees, Federal Hospital Insurance Trust Fund. 1996 Annual Report of the Board of Trustees of the Federal Hospital Insurance Trust Fund. Washington, DC, @ www.HCFA. gov, June 51996.

4. Stoeckle JD. The citadel cannot hold: Technologies go outside the hospital, patients and doctors too. Milbank Q 1995;73:3-17.

5. Institute of Medicine. Improving the Quality of Care in Nursing Homes. Washington, DC: National Academy Press, 1986.

6. Blendon RJ, Donelan $\mathbb{K}$, Hill $\mathbb{C}$, et al. Medicaid beneficiaries and health reform. Health Aff 1993;12:132-143.

7. Weissert CS. Medicaid in the 1990s: Trends, innovations, and the future of the 'PAC-Man' of state budgets. Publis: The Joumal of Federalism 1992;22:93-109.

8. Weissert WG, Cready CM, Pawelak JE. The past and future of home- and community-based long-term care. Milbank Mem Fund Q 1988;66:309-388.

9. Weissert WG, Hedrick SC. Lessons learned from research on effects of community-based long-term care. J Am Geriatr Soc 1994;42:348-353.

10. Wagner ER. Types Of Managed Care Organizations. In: Kongstvedt PR, ed. Essentials of Managed Health Care. Galthersburg, MD: Aspen Publishers, 1995.

11. Miller RH, Luft HS. Managed care plan performance since 1980: A literature analysis. JAMA 1994;271:1512-1519.

12. Physician Payment Review Commission (PPRC). Annual Report to Congress 1997. Washington, DC: PPRC, 1997.

13. Langwell KM, Hadley JP. Capitation and the Medicare program: History, issues, and evidence. Health Care Financ Rev 1986;Annual Supplement:9-20.

14. Brown RS, Clement DG, Hill JW, et al. Do health maintenance organizations work for Medicare? Health Care Financ Rev $1993 ; 15: 7-23$.

15. Harrington C, Newcomer RJ. Social Health Maintenance Organizations: Service use and costs, 1985-89. Health Care Financ Rev 1991;12:37-52.

16. Wrightson CW, McCall N. Cost analyses of the Arizona Health Care Cost Containment System: Lessons from an eleven-year evaluation. A Health Econ Health Serv Res 1995;15:79-97.

17. McCall N, Wrightson CW, Korb J. et al. Evaluation of Arizona's Health Care Cost Containment System Demonstration. Final Report. San Francisco, CA: Laguna Research Associates, February 1996.

18. Irvin K, Riley T, Booth M, et al. Managed Care for the Elderly: $A$ Profile of Cument Initiatives. Portland, ME: The Center for Health Policy Development, National Academy for State Health Policy, November 1993.

19. Eng CE, Pedulla J, Eleazer GP, et al. Program of All-Inclusive Care for the Elderly (PACE): An innovative model of integrated geriatric care and financing. $J$ Am Geriatr Soc 1997;45:223-232. 
20. Garfinkel SA, Schlenger WE, McLeroy KR, et al. Choice of payment plan in the Medicare Capitation Demonstration. Med Care 1986;24:628-640.

21. McCombs JS, Kasper JD, Riley GE. Do HMOs reduce health care costs? A multivariate analysis of two Medicare HMO demonstration projects. Health Sev Res 1990:25:593-613.

22. Rossiter LF, Nelson LM, Adamache KM. Service use and costs for Medicare beneficiaries in risk-based HMOs and CMPs: Some interim results from the National Medicare Competition Evaluation. Am ol Public Health 1988;78:937-943.

23. Retchin SM, Brown B. The quality of ambulatory care in Medicare health maintenance organizations. Am $J$ Public Health 1990;80:411-415

24. Retchin SM, Brown B. Management of colorectal cancer in Medicare health maintenance organizations. \& Gen Intern Med 1990;5:110-114.

25. Retchin SM, Brown B. Elderly patients with congestive heart failure under prepaid care. Am J Med 1991;90:236-242.

26. Retchin SM, Preston J. Effects of cost containment on the care of elderly diabetics. Arch Intern Med 1991;151:2244-2248.

27. Retchin SM, Clement, DG, Rossiter LF, et al. How the elderly fare in HMOs: Outcomes from the Medicare Competition Demonstrations. Health Serv Res 1992;27:651-669.

28. Brown RS, Hill .JW. The effects of Medicare risk HMOs on Medicare costs and service utilization. In: Luft HS, ed. HMOs and the Elderly. Ann Arbor, MI: Health Administration Press, 1994.

29. Retchin SM, Clement DG, Brown RS. Care of patients hospitalized with strokes under the Medicare risk program. In: Luft HS, ed. HMOs and the Elderly. Ann Arbor, MI: Health Administration Press, 1994.

30. Hellinger FJ. Selection bias in health maintenance organizations: Analysis of recent evidence. Health Care Financ Rev 1987;9:55-63.

31. Riley GF, Lubitz J, Rabey E. Enrollee health status under Medicare risk contracts: An analysis of mortality rates. Health Serv Res 1991;26:137-163.

32. Lichtenstein R, Thomas JW, Adams-Watson J, et al. Selection bias in TEFRA at-risk HMOs. Med Care 1991;29:318-331.

33. Riley G, Tudor C, Chiang Y, et al. Health Status of Medicare enrollees in HMOs and fee for-service in 1994. Health Care Financ Rev 1996; 17:65-76.

34. Wisner CR, Feldman R, Dowd B. The Twin Cities Medicare Health Plans Market: Choice, cost, and health status. In: Luft HS, ed. HMOs and the Elderly. Ann Arbor, MI: Health Administration Press, 1994.

35. Iversen LH, Oberg CN, Polich CL. The availability of long-term care services for Medicare beneficiaries in health maintenance organizations. Med Care 1988;26:918-925.

36. Ricketts TC, Slifkin RT, Johnson-Webb KD. Patterns of health maintenance organization service areas in rural counties. Health Care Financ Rev 1995;17:99-113.

37. HMO-PPO Digest 1995. Kansas City, MI: Hoechst Marion Roussell, Inc., 1995.

38. Hurley RE, Bannick RR. Utilization managers in Medicare Risk Contract HMOs: Frora control to collaboration. Qual Rev Bull 1993;19:131-137.

39. Friedman B, Kane RL. HMO medical directors' perceptions of geriatric practice in Medicare HMOs. I Am Geriatr Soc 1993;41:1144-1149.

40. Fox PD, Heinen L, Kramer AM, et al. Initiatives in Service Delivery for the Elderly in HMOs. Prepared for The Robert Wood Johnson Foundation. Washington, DC: Lewin/ICF, 1991.

41. Eppig FJ, Poisal JA. Prescribed medicines: A comparison of FFS with HMO enrollees. Health Care Financ Rev 1996;17:213-214.
42. Nelson L, Gold M, Brown R. Access to Care in Medicare Managed Care: Results from a 1996 Survey Enrollees and Disenrollees, Selected Research Series, No. 7. Washington DC: Physician Payment Review Commission, November 1996.

43. Zarabozo C, Taylor C, Hicks J. Medicare managed care: Numbers and trends. Health Care Financ Rev 1996;17:243-261.

44. Riley GF, Potosky AL, Lubitz JD. Stage of cancer diagnosis for Medicare $\mathrm{HMO}$ and fee-for-service enrollees. Am J Public Health 1994;84:1598-1604.

45. Carlisle DM, Siu AL, Keeler EB, et al. HMO vs FFS care of older persons with acute myocardial infarction. Am I Public Health 1992:82:1626-1630.

46. Clement DG, Retchin SM, Brown RS, et al. 1994. Access and outcomes of elderly patients enrolled in managed care. JAMA 1994:271:1487-1492.

47. Ware JE Jr, Bayliss MS, Rogers WH, et al. Differences in 4-year health outcomes for elderly and poor, chronically ill patients treated in HMO and fee-for-service systems: Results from the Medical Outcomes Study. JAMA 1996;276:1039-1047.

48. Shaughnessy PW, Schlenker RE, Hittle DF. Home health care outcomes under capitated and fee-for-service payment. Health Care Financ Rev 1994;16:187-221.

49. Wan TTH. The effect of managed care on health services use by dually eligible elders. Med Care 1989;27:983-1001.

50. McCall N, Jay ED, West $R$. Access and satisfaction in the Arizona Health Care Cost Containment System. Health Care Financ Rev 1989;11:63-77.

51. McCall N, Turner P, Wrightson CW, et al. Evaluation of the Arizona Health Care Cost Containment System Demonstration: First Outcome Report. San Francisco, CA: Laguna Research Associates, July 1991.

52. Newcomer R, Manton K, Harrington C, et al. Case mix controlled service use and expenditures in the Social/Health Maintenance Organization Demonstration. J Geront A Biol Sci Med Sci 1995;50A:M35-M44.

53. Newcomer R, Harrington C, Preston S. Satisfaction in the Social/Health Maintenance Organization: A comparison of members, disenrollees, and those in fee-for-service. In: Luft HS, ed. HMOs and the Elderly. Ann Arbor, MI: Health Administration Press, 1994.

54. Manton KG, Newcomer RJ, Lowrimore GR et al. Social/Health Maintenance Organization and fee-for-service health outcomes over time. Health Care Financ Rev 1993;15:173-202.

55. Branch LG, Coulam RF, Zimmerman YA. The PACE evaluation. Initial findings. Gerontologist 1995;35:349-359.

56. Weissert WG, Lesnick T, Musliner M, et al. Cost-savings from home and community based services: Arizona's capitated Medicaid longterm care program. J Health Pol Policy Law 1997;22:1329-1357.

57. Dawson D, Hendershot G, Fulton J. Aging in the eighties: Functional limitations of individuals age 65 years and over. In: Advanced Dala From Vital and Health Statistics, No 133. Hyattsville, MD: National Center for Health Statistics, June 1987;10.

58. Weissert WG, Scanlon WJ, Wan TTH, et al. Care for the chronically ill: Nursing home incentive payment experiment. Health Care Financ Rev 1983;5:41-49.

59. Weissert WG, Wan T, Livieratos B, et al. Effects and costs of daycare services for the chronically ill: A randomized experiment. Med Care 1980;18:567-584.

60. Carcagno GI Kemper P. The evaluation of the National Long Term Care Demonstration. 1. An overview of the channeling demonstration and its evaluation. Health Serv Res 1988;23:1-22. 